\title{
A FATEC SENAI Roberto Mange Frente ao Planejamento Estratégico e Educação Superior
}

Anápolis é uma cidade conceituada com forte vocação para a atividade industrial. O município é o terceiro do Estado de Goiás em população, aproximadamente 350.000 habitantes. É também o segundo no ranking de competitividade e desenvolvimento, por estar no centro da região mais desenvolvida do Centro-Oeste brasileiro. A região possui Produto Interno Bruto (PIB) estimado em R $\$ 230$ bilhões, representando 6\% do PIB brasileira e quase $70 \%$ do PIB da região Centro-Oeste. Anápolis também se encontra num estado que apresenta como política consistente os incentivos financeiros e fiscais. A Escola SENAI de Anápolis surgiu em 1952, como extensão da Delegacia Regional de São Paulo, e logo transformou-se no polo de formação de profissionais para todo o Estado. Passada mais de uma década, em 1966, foi construída a segunda escola SENAI em Goiás, esta, na capital do Estado, está já sob a jurisdição da então criada da Federação das Indústrias do Estado de Goiás ( FIEG).

O Mapa Estratégico da Indústria 2013-2022 indica ações que visam: (1) ampliar a qualidade da educação profissional e o ensino superior, de acordo com a necessidade da indústria, consolidando a metodologia SENAI de Educação Profissional; (2) orientar a atuação do SENAI em educação profissional e educação superior, de forma a garantir que a demanda de qualificação requerida pela indústria seja atendida com uniformidade e qualidade pautadas pela metodologia SENAI.

Conforme indica o Planejamento Estratégico Integrado SESI-SENAI-IEL 2015-2022 do Serviço Nacional de Aprendizagem Industrial (Departamento Nacional), há as seguintes diretrizes:
1. EDUCAÇÃO, INOVAÇÃO E PRODUTIVIDADE: Alinhado ao Mapa Estratégico da Indústria, o plano enfatiza a busca pela qualidade da educação básica, apresentando o ideal de elevar as escolas do SESI a patamares de referência em excelência educacional e ,ainda, continuando a perseguir com firmeza e inovação uma educação para o mundo do trabalho. Em sintonia com os fatores-chave de educação e inovação, após alto desempenho em volume de matrículas nos últimos anos, o SENAI tem o desafio de consolidar a qualidade da sua metodologia, ampliar o acesso à educação profissional, por meio de plataformas flexíveis de ensino, formar engenheiros e tecnólogos, a fim de atender à demanda da indústria, promover o incremento da inovação de produtos e processos nas empresas, por meio de projetos de pesquisa e desenvolvimento, bem como, obter sustentabilidade dos serviços técnicos e tecnológicos. O Planejamento Estratégico Integrado SESI-SENAI-IEL 2015-2022 define o posicionamento dessas entidades e reafirma a determinação de vencer os desafios de atender às demandas da indústria brasileira, no apoio à sua competitividade e no desenvolvimento sustentável do Brasil.

\section{EDUCAÇÃO PROFISSIONAL, EDUCAÇÃO} BÁSICA E GESTÃO EMPRESARIAL: A atual situação da qualificação dos profissionais representa, para a indústria, fator de risco, pois reduz e dificulta a produtividade das operações, porém, representa grande oportunidade para o SESI, o SENAI e o IEL, pois as entidades têm um portfólio de serviços voltados exatamente para essa necessidade. Outra oportunidade, também importante, é a disponibilidade 
e a oferta de intercâmbios, que dão a oportunidade de internacionalizar o conhecimento, como, por exemplo, o Ciência Sem Fronteiras, um dos projetos de maior destaque financiado pelo governo.

\section{INOVAÇÃO E SERVIÇOS TÉCNICOS E} TECNOLÓGICOS: Inovação é um diferencial competitivo para as indústrias e está atrelado à melhoria do desempenho, à redução de custos e às empresas mais enxutas. De acordo com a Pesquisa de Inovação, o Brasil investe pouco em inovação quando comparado aos Estados Unidos e à China, que investiram 415 e 208 bilhões de dólares em 2011, respectivamente, enquanto o Brasil investiu 27 bilhões de dólares.Pode-se dizer que essa diferença de investimento é uma fraqueza para o país e uma ameaça para a industria, mas uma oportunidade para SESI, SENAI e IEL, uma vez que investir em inovação, de acordo com as respostas dadas pelas empresas inovadoras, pode significar um aumento da competitividade.

4. DEFINIÇÃO DE INOVAÇÃO: Empresas tornamse competitivas quando promovem mudanças em seus processos que permitem o aumento da sua produtividade, criam novos produtos, atingem novos mercados e aumentam sua margem de lucro, ou seja, quando promovem a inovação. Em outras palavras, inovação é uma ideia lucrativa que permite à empresa alcançar e superar a concorrência, podendo ocorrer em quatro tipos: de produto, de processo, organizacional ou de marketing. Nos negócios, a inovação raramente floresce de um momento de inspiração, mas, sim, a partir de uma análise fria de sete tipos de oportunidade: ocorrências inesperadas, novos conhecimentos, mudanças de percepção, mudanças demográficas, mudanças no mercado, necessidades do processo e incongruências.

Se a indústria local, regional e nacional se moderniza para ser competitiva, a instituição SENAI que ela criou e mantém não poderia deixar de incorporar os avanços tecnológicos que invadem todos os setores da vida. É o que as empresas sempre cobraram do SENAI. Desta forma, sem abandonar os cursos básicos e técnicos que o mercado continua necessitando, em 2004 o então Centro de Educação Profissional SENAI eleva-se à Faculdade de Tecnologia SENAI Roberto Mange (FATEC/RM).
Com isso, vem preparando, também, profissionais para o campo da gestão, da tecnologia e da inovação, ofertando o Curso Superior de Tecnologia Processos Químicos, e as várias opções dos cursos de pós-graduação lato sensu.

$\mathrm{Na}$ constante busca de atender aos anseios da indústria, dando-lhe opções para retroalimentar-se com o que lhe é de mais importante, profissionais devidamente qualificados para as incessantes necessidades geradas, a FATEC SENAI RM passa a ofertar, a partir desse ano, 2014, também o Curso Superior de Tecnologia em Manutenção Industrial. Tal curso visa suprir à demanda de profissionais capazes de aplicar as competências, habilidades, atitudes e valores voltados para os processos de manutenção industrial eletromecânicos, sendo capazes de implantar sistemas de gerenciamento e manutenção, aptos a intervir na manutenção, gestão e supervisão de processos de produção, controle de produtividade e de qualidade, aplicação e desenvolvimento de pesquisa e inovação tecnológica, sempre, observando aspectos ligados aos setores de qualidade, meio ambiente e segurança, contribuindo com o desenvolvimento sustentável de Goiás. Também é mister citar que a FATEC, nesse momento, otimiza recursos para dar inicio às ações do Instituto SENAI de Tecnologia (IST).

Seja desenvolvendo projetos de pesquisa tecnológica ou prestando Serviços Técnicos e de Inovação, todas estas atividades são inerentes à missão da FATEC/RM de promover a educação profissional e tecnológica, a inovação e a transferência de tecnologias industriais para elevar a competitividade da indústria goiana. Poucas instituições de ensino terão contribuído tão significativamente para o desenvolvimento tecnológico, em Anápolis e no Brasil, e não poderia ser diferente, uma vez que foi criada para servir a indústria.

\section{Wilson de Paula e Silva*}

Gerente de Educação e Tecnologia da Faculdade de Tecnologia SENAI Roberto Mange

*E-mail: wsilva.senai@sistemafieg.org.br 